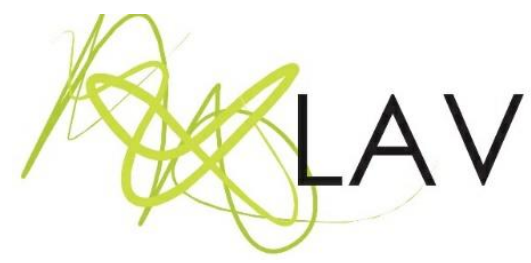

\title{
Relatos de uma pesquisa com jovens estudantes de Juiz de Fora: audiovisual e gênero
}

Reports of a survey with young students from Juiz de Fora: audiovisual and gender

\author{
Carla Silva Machado \\ Pontifícia Universidade Católica do Rio de Janeiro \\ Rosália Maria Duartei \\ Pontifícia Universidade Católica do Rio de Janeiro
}

\begin{abstract}
Resumo
O presente artigo trata das relações entre jovens estudantes do segundo ciclo do Ensino Fundamental, da cidade de Juiz de Fora/MG, com filmes que têm outros jovens como protagonistas. O foco da discussão são suas percepções quanto às representações de gênero nos filmes. Para abordar essas impressões, recorreu-se a resultados de um estudo desenvolvido com jovens de uma Escola Municipal da rede Pública. A pesquisaintervenção teve como principal procedimento a realização de oficinas de visualização e discussão de filmes, cujo objetivo era entender a relação daqueles jovens com o audiovisual. Uma das questões que emergiu, no desenrolar das atividades, tratou das representações de gênero construídas no contato com narrativas audiovisuais. Os resultados foram discutidos à luz dos estudos de comunicação latino-americanos, tendo como principais referências Jésus Martín-Barbero e Néstor García-Canclini, e dos estudos de gênero e de suas relações com as mídias, desenvolvidos por Guacira Louro.
\end{abstract}

Palavras-chave: Jovens, audiovisual, gênero.

\begin{abstract}
This article focuses on the relationship between young students in the second cycle of elementary school from the city of Juiz de Fora/MG and films that have young people as protagonists. The focus of the discussion is these young people's perceptions of gender representations in films. To address these perceptions, we used the results of a study developed with young people of a school in the municipal public school system. The research-intervention had as main procedure the implementation of workshops for viewing and discussing films, whose objective was to understand the relationship of those young people with the audiovisual. One of the issues that emerged in the course of the activities was the gender representations built in contact with audiovisual narratives. The results were discussed in the light of Latin American communication studies, with Jésus Martín-Barbero and Néstor García-Canclini as the main references, and gender studies and their relations with the media, developed by Guacira Louro.
\end{abstract}

Keywords: Young People, audiovisual, gender. 


\section{O cenário: uma introdução}

O presente artigo trata das relações entre jovens, audiovisual e gênero no contexto de um estudo realizado com estudantes da cidade de Juiz de Fora, Minas Gerais. Cabe destacar a relevância do audiovisual no Brasil, que envolve cinema, televisão aberta, canais por assinatura, DVDs e conteúdos multimídia veiculados na Internet, os chamados streamings.

Para Martín-Barbero (2013), há uma forte identificação das massas latinoamericanas com a imagem. Em sua perspectiva, as pessoas se reconhecem nas produções audiovisuais e tomam a ficção como instrumento para compreender o real, em um movimento que vai do "desconhecimento ao re-conhecimento da identidade" (MARTÍN-BARBERO, 2013, p. 171). No Brasil, a forte relação com o audiovisual de ficção é especialmente significativa entre jovens, que são os principais consumidores de plataformas de streaming e de repositórios de vídeos.

Ao tratarmos das relações entre jovens e audiovisuais, é necessário mencionar que, assim como Sarlo (2013, p. 49), entendemos que juventude não é somente uma questão geracional, mas é principalmente uma forma de inserção na sociedade, com o compartilhamento de um conjunto de práticas, valores e posturas associados a uma 'estética da vida cotidiana'. Segundo a autora, é possível notar os estilos juvenis a partir das roupas que os jovens usam, dos modos de andar, de falar e de se relacionar com os outros. Existem, para a autora, culturas juvenis ou modos de ser jovem que não são característicos de um lugar específico. Com a ampla difusão de imagens e visões de mundo pela internet, a mundialização da cultura, como a define Renato Ortiz (1994), faz com que seja possível perceber atravessamentos estéticos nas juventudes de diferentes países. Isso permite compreender como jovens de uma cidade do interior de Minas Gerais se conhecem e se reconhecem em personagens jovens de filmes produzidos em outros países, a partir de referências de outra língua e cultura.

As reflexões apresentadas aqui têm como base os resultados de uma pesquisaintervenção, ancorada na visualização ${ }^{1}$ compartilhada de filmes com temáticas e personagens juvenis, realizada com cerca de 30 jovens, com idades entre 12 e 14 anos, de uma Escola Municipal da cidade de Juiz de Fora. Na maioria das atividades, contamos

\footnotetext{
${ }^{1} \mathrm{Na}$ pesquisa, optou-se por usar o termo 'visualização', pois foram desenvolvidas oficinas em que os jovens assistiam aos filmes e, após o momento de exibição, havia momentos de reflexão e discussão da construção das narrativas audiovisuais, ocorrendo, portanto, mediação da pesquisadora com os jovens. Dessa forma, os termos exibição e fruição não seriam apropriados nesse contexto de interação entre os jovens, o filme e o debate proposto.
}

Revista Digital do LAV - Santa Maria - vol. 13, n. 2, p. 254 - 273 - mai./ago. 2020 ISSN 1983 - 7348 http://dx.doi.org/10.5902/1983734844055 
com a participação de 16 meninas e 14 meninos. O estudo teve como foco analisar como esses jovens percebiam os modos de representação das juventudes nos filmes exibidos.

\section{A pesquisa em ação}

A pesquisa mencionada ocorreu durante todo o ano letivo de 2016. Desenvolvida como pesquisa-intervenção, envolveu a realização de oficinas de visualização de filmes, registros impressos e em diário de campo, além de questionários, audiogravações e videogravações de atividades desenvolvidas pelos participantes. As atividades de pesquisa foram realizadas no contraturno das aulas do Ensino Fundamental da Escola, em forma de oficinas, como projeto extracurricular, ligado à formação integral dos alunos. Buscou-se criar, conforme Dionne (2007), um vínculo de cooperação entre atores e pesquisadores, o que contribui para uma aproximação maior entre eles. Nas palavras do autor:

A elaboração e a partilha dos conhecimentos ocorrem em relações de convivência que incitam, ao mesmo tempo, o pesquisador a coletar os conhecimentos derivados da ação e o ator a contribuir diretamente para a produção de conhecimentos. A divisão social do trabalho profissional entre pesquisador e o participante-ator tende a desvanecer-se, tornando-se um coletivo engajado em uma mesma intervenção (DIONNE, 2007, p. 34).

Entendemos o trabalho com oficinas, assim como Andrade e Lucinda (2011), como um espaço de desenvolvimento prático de temas do cotidiano. Partindo do conceito clássico de oficina como local de consertos ou, ainda, "de aprendizagem de certo grau de habilidades, desenvolturas ou competências ao campo das artes" (ANDRADE; LUCINDA, 2011, p. 258), podendo ser um espaço em que se "aprende trabalhando". Para esses autores, há duas características essenciais para uma oficina: "(1) trabalho coletivo e (2) processos de ensino-aprendizagem que integra teoria e prática" (Idem, p. 259). No desenrolar da pesquisa, essas duas características foram trabalhadas. Durante o processo de pesquisa, evidenciou-se a relação direta das oficinas com a pesquisa-ação ou pesquisa-intervenção, visto que, tendo realizado as atividades propostas, os participantes não saíram da mesma forma que entraram, ou seja, mesmo que não possam ser mensuradas, as oficinas desenvolvidas durante a pesquisa, modificaram o modo de ver filmes dos atores envolvidos.

É importante conhecer a Escola em que a pesquisa foi realizada, seu entorno e os jovens que participaram da pesquisa, visto que há algumas especificidades, por exemplo, o fato de a Escola ser o único estabelecimento público no bairro. Dessa forma, ela 
cumpre um papel que vai além do ensinar, porque ocorrem várias atividades culturais em projetos de contraturno que, muitas vezes, são a única fonte de aproximação dos jovens estudantes com a produção cultural (dança, teatro, capoeira, cinema e outros). Além disso, eventualmente, a gestão da escola e seus professores promovem atividades para as mães dos alunos (cursos de tapeçaria, tricô, crochê e outros), ressaltando que a Escola é também um espaço de interação com a comunidade do bairro e as famílias dos alunos.

Até o início dos anos 2000, muitos bairros da região oeste da cidade, onde a escola está situada, eram formados basicamente por propriedades rurais e casas de lazer e descanso, tendo em vista que a região é afastada do centro da cidade e possui muita área verde. A partir desse período, muitos loteamentos de casas populares foram sendo construídos, alguns vinculados ao Programa Minha Casa, Minha Vida, do Governo Federal. Devido a isso, houve um crescimento desordenado na região, que não conta com espaços públicos de cultura e lazer e sofre com ruas sem asfalto e transporte público insuficiente. Grande parte dos alunos da escola referida mora nesses loteamentos, que estão muito próximos à Escola.

A Escola possui aproximadamente 300 alunos. Desse total, do $6^{\circ}$ ao $9^{\circ}$ ano há 100 alunos e uma turma para cada ano de escolaridade. Desde a implementação do tempo integral, várias mudanças ocorreram para atender às necessidades dos alunos e da comunidade, inclusive na infraestrutura, mas ainda há muito que ser melhorado, pois há poucas salas disponíveis e escassos equipamentos, como TV, projetor e DVD, bem como falta de conexão com a Internet.

A partir dos dados informados pelos alunos na edição de 2015 da Prova Brasil (disponibilizados pelo QedU²), levantamos o perfil socioeconômico dos jovens dessa Escola. A maioria dos alunos pode ser classificada como pertencente às classes populares. Na época, um dos alunos não tinha nenhum aparelho de TV em casa, o que demonstra que, apesar de ser um bem popularizado, ainda havia quem não tivesse acesso a canais de TV aberta. Quase metade dos alunos não tinha computador em casa e a maioria dos que tinham contava com apenas um, de uso familiar, o que indica que não era um equipamento de uso pessoal. Entre os respondentes, $70 \%$ moravam com três ou mais pessoas em suas casas e a maior parte compartilhava quarto, banheiro,

\footnotetext{
2 Site criado pela Fundação Lemman e Merit Educacional, que disponibiliza e analisa os dados de avaliações educacionais em Larga Escala. Ressalto que, para esta pesquisa, usei apenas o material bruto disponibilizado pelo site, não me interessando pelas análises feitas, visto que meu objetivo foi traçar um perfil socioeconômico dos sujeitos que frequentam a Escola pesquisada
}

Revista Digital do LAV - Santa Maria - vol. 13, n. 2, p. 254 - 273 - mai./ago. 2020 ISSN 1983 - 7348 http://dx.doi.org/10.5902/1983734844055 
computador, rádio, videocassete e/ou DVD e televisão com os demais membros da família.

Em um questionário respondido para a pesquisa, dezoito alunos (de trinta) responderam que foram poucas vezes ao cinema; apenas três responderam que vão ao cinema todo mês. Para a maioria deles, a TV é o contato mais direto com filmes, o que confirma os estudos de Martín-Barbero, Orozco-Gómez e outros pesquisadores latinoamericanos que apontam a relevância da televisão no acesso à informação e ao entretenimento no continente. As respostas indicavam também que a TV era o principal acesso dos jovens a filmes (treze afirmaram assistir a filmes na TV aberta e nove afirmaram que assistiam pelos canais de TV por assinatura).

Durante a realização das oficinas, os jovens assistiram a oito filmes, cujas exibições foram seguidas de debates e de atividades complementares (desenho, criação de personagens, relatos de experiência etc.), tendo como ponto de partida os filmes vistos. Os quatro primeiros filmes exibidos integravam o ranking dos 20 filmes com maiores bilheterias nas salas de cinema do Brasil, no ano de 2014, e apresentavam jovens como protagonistas. Optou-se pelo ano de 2014 , pois seriam filmes que poderiam ser encontrados em DVD (o sinal de Internet da Escola não permitia a exibição de filmes em plataformas de streaming) e não haviam chegado à TV aberta. Assim, poderiam ainda não ter sido vistos pelos jovens participantes da pesquisa, pois, muitos, tinham acesso a filmes quase sempre pela TV aberta. Como eram filmes inéditos para eles, acreditamos que despertariam mais interesse. São eles:

1) A culpa é das estrelas - dirigido por Josh Boone, inspirado no romance de John Green, lançado no Brasil em 5 de junho de 2014, classificado como drama (125 min - não recomendado para menores de 12 anos);

2) Malévola - dirigido por Robert Stromberg, lançado no Brasil em 29 de maio de 2014, classificado como fantasia/aventura (96 min - não recomendado para menores de 10 anos);

3) X-Men: dias de um futuro esquecido, dirigido por Bryan Singer, lançado no Brasil em 22 de maio de 2014, um filme de ação (131 min - não recomendado para menores de 12 anos);

4) Jogos vorazes: a esperança - parte 1, dirigido por Francis Lawrence, lançado no Brasil em 19 de novembro de 2014, classificado como filme de ficção científica/aventura (193 min - não recomendado para menores de 14 anos).

Após a visualização desses filmes, foi solicitado aos participantes que indicassem outros títulos/produções que gostariam de ver, sendo os mais votados os escolhidos para 
as oficinas seguintes. Ao todo, treze filmes foram indicados e defendidos pelos jovens, dos quais três obtiveram mais votos e fizeram parte das oficinas. São eles:

1) As crônicas de Nárnia: o Leão, a Feiticeira e o Guarda-Roupa - dirigido por Andrew Andamson, lançado no Brasil em dezembro de 2005, um filme de fantasia/aventura (150 min);

2) João e Maria: caçadores de bruxas - dirigido por Tommy Wirkola, um filme de fantasia/ação, lançado no Brasil em janeiro de 2013 (98 min);

3) Jurassic World: o mundo dos dinossauros - dirigido por Colin Trevorrow, um filme de ficção científica, lançado no Brasil em junho de 2015 (124 min).

Notamos, a partir das escolhas, que o padrão narrativo, a nacionalidade e o tipo de enredo dos filmes permaneceram os mesmos, ou seja, eram campeões de bilheteria, produzidos nos grandes estúdios dos Estados Unidos, em sua maioria com protagonistas com superpoderes, que lutavam em mundos paralelos, envolvendo bastante fantasia.

Como última atividade do projeto, a pesquisadora sugeriu um filme brasileiro, As melhores coisas do mundo (2010), dirigido por Laís Bodansky e classificado como drama. Essa indicação teve como objetivo apresentar aos participantes um modelo alternativo de narrativa audiovisual com jovens como protagonistas, com uma estrutura argumentativa mais realista e mais próxima da realidade brasileira.

Neste artigo, apresentaremos algumas reflexões que emergiram da análise das experiências de visualização dos filmes, dando ênfase a atividades desenvolvidas a partir da visualização de $X$-Men: dias de um futuro esquecido e de Jogos vorazes: a esperançaparte 1 . Abordaremos, em especial, as questões relativas a como os jovens participantes das oficinas percebiam a construção de personagens femininas e masculinas nos filmes que conheciam e nos filmes que visualizaram durante a pesquisa.

\section{Algumas relações possíveis entre juventude, audiovisual e gênero}

De acordo com Veiga (2017, p. 1355), no começo dos anos 1990, o conceito de gênero surgiu com mais ênfase "na crítica teórica do cinema", denunciando o aparato cinematográfico como "tecnologia do gênero". A partir de então, os modos de representação de gênero, nas narrativas audiovisuais, tornaram-se um importante objeto de estudo tanto nos estudos de gênero quanto nos estudos sobre o próprio cinema. A maior parte desses estudos aponta uma forte desigualdade entre o lugar reservado ao feminino e ao masculino nas narrativas cinematográficas, com forte prevalência da voz 
masculina, mesmo quando a protagonista é uma personagem de gênero feminino, embora registrem também mudanças progressivas nesse padrão, face à resistência e persistência das mulheres do cinema e dos movimentos feministas (KAPLAN, 1995; ALVES e COELHO, 2015; KAMITA, 2017; LUSVARGHI; ALVIM e NASCIMENTO, 2018).

Anderson e Daniels (2016) divulgaram uma pesquisa encomendada pela Polygraph, na qual analisaram cerca de dois mil roteiros de filmes estadunidenses que entraram em cartaz entre 1929 e 2015 e constataram que, na maioria dos filmes, haviam mais falas de personagens masculinas do que femininas. Entendemos que a fala indica presença, legitimidade, reconhecimento e visibilidade, portanto, está ligada à representatividade e ao lugar de destaque que as personagens assumem no imaginário do espectador.

Ainda nessa pesquisa, os autores também destacaram as desigualdades de 'fala' nas faixas etárias das personagens: "enquanto os homens acima dos 40 anos têm mais falas, as mulheres, à medida que envelhecem, têm menos falas nos filmes" (2016, s.p.), o que mostra que a representatividade feminina no cinema está associada à juventude.

Tomando como referência as questões acima mencionadas acerca dos modos de representação de gênero no cinema, apresentamos alguns resultados da análise dos registros de oficinas de visualização de filmes e de atividades complementares, desenvolvidas no estudo realizado com jovens estudantes de Juiz de Fora, em que essa temática ficou evidenciada.

Em quatro dos oito filmes exibidos, as mulheres eram protagonistas; nos demais, com exceção do último (que não fará parte do nosso corpus analítico, por apresentar características bastante diferentes dos outros), elas tinham papel de destaque. Porém, mesmo como protagonistas, em vários momentos, todas as personagens femininas acabavam agindo em função de personagens masculinas ou se deixando levar por decisões de outras pessoas, em geral, homens. Percebe-se, nessas narrativas, que as falas das personagens masculinas têm mais destaque e influenciam mais o desfecho da trama do que as das personagens femininas.

Louro $(2008,2013)$, ao analisar representações de gênero no cinema, assinala que é possível notar transformações nas últimas décadas. Segundo a autora, predominaram dois tipos de papéis femininos, que se contrapunham: "a mulher respeitável e a prostituta" (LOURO, 2013, p. 175) e ambas serviam de escada para a personagem masculina, que era a protagonista de fato. Ao analisar as personagens femininas, nos filmes dos anos 1950, a autora percebe que:

Revista Digital do LAV - Santa Maria - vol. 13, n. 2, p. 254 - 273 - mai./ago. 2020 ISSN 1983 - 7348 http://dx.doi.org/10.5902/1983734844055 
Num tempo de pós-guerra, parecia necessário, de algum modo, deter ou reverter o avanço feminino que fora possibilitado pelo longo conflito. O cinema ajudaria a promover a "volta ao lar" e a recomposição da estrutura familiar tradicional. Roteiros de inúmeras comédias, romances ou dramas passavam a tratar daquele que se colocava como o novo dilema feminino: a escolha entre a família (casamento e filhos) ou a carreira profissional. Um happy end recompensava as mulheres que escolhiam certo, isto é, o lar, enquanto que as outras, muitas vezes representadas como "masculinizadas", duras e amargas, terminavam sós e infelizes (LOURO, 2008, p. 83).

Nos filmes vistos com os jovens nas oficinas, o enredo não envolve casamento, nem as qualidades das personagens, cujas personalidades são descritas e compostas de forma mais ou menos complexa. Mas, em muitos deles, apesar de diferentes formatos estéticos e narrativos, as mulheres - ainda que empoderadas e seguras de si - são colocadas diante de grandes amores, em situações em que é necessário escolher entre o amor e a guerra. Vale ressaltar que as personagens femininas retratadas nesses filmes, apesar das diferenças, de um modo geral, agem muito mais por impulsos emocionais do que por decisões racionais, levando ao espectador a ideia de que se deixar levar pela emoção é uma característica feminina.

Exemplos dessas características podem ser percebidos em Jogos vorazes, em que a personagem central entra num jogo (uma espécie de reality show) em que sua vida é o prêmio, porém, se não jogar, perderá sua mãe e irmã. Após salvá-las e a si própria, volta novamente ao jogo, desta vez para salvar o homem que ama. As decisões tomadas pela protagonista são na verdade conduzidas por um homem, o Presidente Snow, um ditador que se diverte com o jogo e a manipula. Quando ele perde o controle sobre ela, entra em cena outro homem, Haymitch Albernathy, uma espécie de consultor de imagem, que a transforma em heroína da nação, conduzindo suas falas e suas ações e utilizando-a como instrumento na guerra travada com Snow. Durante boa parte da narrativa, a heroína guerreira se comporta como uma espécie de fantoche, ora manipulada por Albernathy, ora por Snow.

Em Malévola, a protagonista, apesar de forte e cheia de poderes, inicia uma guerra com a família real por se sentir abandonada pelo rei que the havia prometido amor, mas preferiu o poder. Assim, as decisões equivocadas da personagem são tomadas a partir do momento em que ela se sente desprezada pelo homem a quem ama, por isso, a necessidade de vingança.

A personagem Mística, de $X-M e n$, precisa escolher entre o amor de Xavier e o de Magneto. Tomar essa decisão é também a garantia de que ela está tomando partido de 
um dos lados de um conflito imposto à humanidade. Ao longo da narrativa, a personagem se mostra completamente indecisa, ora apoia um lado, ora outro, sem nunca se posicionar definitivamente.

Os modos predominantes de representação do feminino e do masculino nos filmes que integraram as oficinas não produziram estranhamentos ou questionamentos nos jovens participantes da pesquisa, o que sugere que a reflexão sobre o tema não integrava, ainda, as relações deles com esse tipo de filme. Isso ficou mais evidente quando, em uma das oficinas, foi solicitado que escolhessem nomes fictícios pelos quais gostariam de ser identificados nos textos sobre a pesquisa. Participaram desta atividade dezesseis meninas e catorze meninos. Os nomes escolhidos foram: Aline Barros, Bella I, Homem-Aranha, Batman, Hulk, Homem de Ferro, Wolverine, Emma Watson, Kaulder, Claire, Lúcia, Alice I Bela II, Malévola, Thor, Lince Negra, Luna, Mercúrio, Kauan, Olaf, Harry Potter, Coringa, Aruna, Troll, Owen, Maria, Alice II, Hazel Graze, João e Lola. A maioria dos nomes é de personagens de filmes que compuseram as oficinas, porém alguns fazem parte da cultura audiovisual desses jovens e é possível perceber que integram o mesmo padrão narrativo e de composição de personagens. No quadro a seguir, apresentam-se, de forma resumida, as características das personagens escolhidas:

\begin{tabular}{|c|c|c|}
\hline $\begin{array}{c}\text { Nome } \\
\text { escolhido }\end{array}$ & Quem é? & Breve história \\
\hline Bella I & $\begin{array}{l}\text { Protagonista do filme } \\
\text { Crepúsculo. }\end{array}$ & $\begin{array}{l}\text { É uma personagem interpretada pela atriz Kristen } \\
\text { Stewart, é a protagonista da saga Crepúsculo, e } \\
\text { namorada do vampiro Edward. }\end{array}$ \\
\hline $\begin{array}{l}\text { Homem- } \\
\text { Aranha }\end{array}$ & $\begin{array}{l}\text { Herói de vários filmes de } \\
\text { Hollywood, também pode ser } \\
\text { visto em desenhos animados } \\
\text { e jogos. O primeiro filme do } \\
\text { super-herói é de } 1977 \text { e o } \\
\text { último (Homem Aranha: de } \\
\text { volta ao lar) estreou em } 6 \text { de } \\
\text { julho de } 2017 \text { no Brasil. }\end{array}$ & $\begin{array}{l}\text { É um personagem das histórias em quadrinhos do } \\
\text { Universo Marvel, publicadas pela Marvel Comics, criado } \\
\text { em } 1941 \text {. Tanto nos filmes como nos quadrinhos, temos } \\
\text { Peter Parker, um estudante universitário e fotógrafo de } \\
\text { um jornal que foi picado por uma aranha e ganhou } \\
\text { superpoderes. }\end{array}$ \\
\hline Batman & $\begin{array}{l}\text { É a identidade secreta de } \\
\text { Bruce Wayne. Herói de vários } \\
\text { filmes de Hollywood, de } \\
\text { desenhos animados e } \\
\text { quadrinhos. }\end{array}$ & $\begin{array}{l}\text { É um personagem das histórias em quadrinhos publicadas } \\
\text { pela DC Comics. Foi criado pelo escritor Bill Finger e pelo } \\
\text { artista Bob Kane e apareceu pela primeira vez na revista } \\
\text { de maio de } 1939 \text {. Ao contrário dos outros super-heróis, } \\
\text { não tem superpoderes, e usa de seu intelecto para } \\
\text { proteger a cidade fictícia de Gotham City. }\end{array}$ \\
\hline Hulk & $\begin{array}{l}\text { Herói de inúmeros filmes e } \\
\text { desenhos animados. }\end{array}$ & $\begin{array}{l}\dot{E} \text { uma personagem, na história original dos quadrinhos, } \\
\text { que representa o selvagem e poderoso alter ego do Dr. } \\
\text { Robert Bruce Banner, um cientista que foi atingido por } \\
\text { raios gama enquanto salvava um adolescente durante o } \\
\text { teste militar de uma bomba desenvolvida por ele. É um } \\
\text { personagem das histórias em quadrinhos do Universo } \\
\text { Marvel, publicadas pela Marvel Comics, criado em } 1962 \text {. }\end{array}$ \\
\hline $\begin{array}{l}\text { Homem de } \\
\text { Ferro }\end{array}$ & $\begin{array}{l}\text { Assim como o Homem- } \\
\text { Aranha, Hulk, Batman e }\end{array}$ & $\begin{array}{l}\text { É um personagem de quadrinhos publicados pela Marvel } \\
\text { Comics. Sua identidade verdadeira é a do empresário e }\end{array}$ \\
\hline
\end{tabular}

${ }^{3}$ Duas jovens escolheram Alice e outros dois nomes que já haviam sido escolhidos, como todos os outros pesquisados foram chamados por um dos nomes que escolheram, para seguir a mesma norma, uma ficou sendo Alice I e outra, Alice II. O mesmo aconteceu com o nome Bela, uma escolheu a Bella do Crepúsculo (Bella I) e outra a Bela do filme A Bela e a Fera (Bela II).

Revista Digital do LAV - Santa Maria - vol. 13, n. 2, p. 254 - 273 - mai./ago. 2020 ISSN 1983 - 7348 http://dx.doi.org/10.5902/1983734844055 


\begin{tabular}{|c|c|c|}
\hline & $\begin{array}{l}\text { outros, ele } \text { nasceu } \\
\text { quadrinhos, nos } \\
\text { desenho animado e aparece } \\
\text { em vários filmes de } \\
\text { Hollywood. }\end{array}$ & $\begin{array}{l}\text { bilionário Tony Stark, que usa armaduras de alta } \\
\text { tecnologia no combate ao crime. Foi criado em } 1963 .\end{array}$ \\
\hline Wolverine & $\begin{array}{l}\text { Personagem do filme } X \text {-Men: } \\
\text { dias de um futuro esquecido } \\
\text { e da cinessérie } X-M e n .\end{array}$ & $\begin{array}{l}\text { É um mutante que possui sentidos sobre-humanos, } \\
\text { atributos físicos melhorados e uma poderosa capacidade } \\
\text { regenerativa. É um personagem das histórias em } \\
\text { quadrinhos do Universo Marvel, publicadas pela Marvel } \\
\text { Comics. Vivido na série de filmes } X \text {-Men pelo ator Hugh } \\
\text { Jackman. }\end{array}$ \\
\hline $\begin{array}{l}\text { Emma } \\
\text { Watson }\end{array}$ & $\begin{array}{l}\text { Atriz da cinessérie Harry } \\
\text { Potter. }\end{array}$ & $\begin{array}{l}\text { É uma atriz britânica, conhecida por interpretar Hermione } \\
\text { Granger nos filmes da série Harry Potter e também a } \\
\text { protagonista de } A \text { Bela e a Fera, além de outros filmes } \\
\text { dirigidos ao público jovem. }\end{array}$ \\
\hline Kaulder & $\begin{array}{l}\text { Protagonista do filme } 0 \\
\text { último caçador de bruxas. }\end{array}$ & $\begin{array}{l}\text { É um personagem vivido por Vin Diesel, ator da cinessérie } \\
\text { Velozes e furiosos, Kaulder é um imortal caçador de } \\
\text { bruxas que tem como tarefa salvar Nova Iorque. }\end{array}$ \\
\hline Claire & $\begin{array}{l}\text { Personagem do filme Jurassic } \\
\text { World: o mundo dos } \\
\text { dinossauros. }\end{array}$ & $\begin{array}{l}\text { É uma personagem interpretada por Bryce Dallas Howard; } \\
\text { é a mocinha do filme e gerente de operações do Jurassic } \\
\text { Park. }\end{array}$ \\
\hline Lúcia & $\begin{array}{l}\text { Uma das protagonistas do } \\
\text { filme As crônicas de Nárnia: o } \\
\text { Leão, a Feiticeira e o Guarda- } \\
\text { Roupa. }\end{array}$ & $\begin{array}{l}\text { É uma personagem interpretada pela atriz britânica } \\
\text { Georgie Henley, é a irmã mais nova de Pedro, Suzana e } \\
\text { Edmundo. É responsável pela descoberta de Nárnia, um } \\
\text { mundo paralelo. }\end{array}$ \\
\hline Alice I e II & $\begin{array}{l}\text { Protagonista de Alice através } \\
\text { do espelho. }\end{array}$ & $\begin{array}{l}\text { É uma personagem representada pela atriz australiana de } \\
\text { ascendência polonesa Mia Justine Reid, encontra um } \\
\text { espelho mágico em uma festa, atravessa-o e vai ao país } \\
\text { das Maravilhas, onde sua função é ajudar o chapeleiro } \\
\text { mágico. }\end{array}$ \\
\hline Bela II & $\begin{array}{l}\text { Protagonista do filme } A \text { Bela e } \\
\text { a Fera. }\end{array}$ & $\begin{array}{l}\text { É uma personagem interpretada pela atriz britânica Emma } \\
\text { Watson, é a mocinha do filme inspirado no conto de fadas } \\
\text { de mesmo nome. }\end{array}$ \\
\hline Malévola & $\begin{array}{l}\text { Personagem do filme } \\
\text { Malévola. }\end{array}$ & $\begin{array}{l}\text { É uma personagem interpretada por Angelina Jolie. } \\
\text { Quando jovem, vive uma desilusão amorosa que a } \\
\text { transforma em uma mulher vingativa. }\end{array}$ \\
\hline Thor & $\begin{array}{l}\text { Personagem da mitologia } \\
\text { germânica, conhecido como } \\
\text { Deus do Trovão. Foi } \\
\text { transformado em quadrinhos } \\
\text { e teve versões em desenho } \\
\text { animado e filmes. }\end{array}$ & $\begin{array}{l}\text { É um personagem que teve versões em quadrinhos em } \\
\text { editoras como Fox Feature Syndicate e DC Comics, } \\
\text { porém, a sua versão mais famosa é da Marvel Comics, } \\
\text { também para o cinema. Sua arma é um martelo, } \\
\text { referência à cultura viking. }\end{array}$ \\
\hline $\begin{array}{l}\text { Lince } \\
\text { Negra }\end{array}$ & $\begin{array}{l}\text { Personagem do filme } X \text {-Men: } \\
\text { dias de um futuro esquecido. }\end{array}$ & $\begin{array}{l}\text { É uma personagem das histórias em quadrinhos do } \\
\text { Universo Marvel, publicadas pela Marvel Comics. No filme, } \\
\text { é representada pela atriz Ellen Page. Possui a capacidade } \\
\text { de teletransporte e tem a missão de levar Wolverine para } \\
\text { o passado no filme de } 2014 \text {. }\end{array}$ \\
\hline Luna & $\begin{array}{l}\text { Personagem do desenho } \\
\text { animado brasileiro } O \text { show da } \\
\text { Luna. }\end{array}$ & $\begin{array}{l}\text { É uma série de TV de animação brasileira criada e dirigida } \\
\text { por Célia Catunda e Kiko Mistrorigo, produzida por Ricardo } \\
\text { Rozzino, da produtora TV PinGuim, exibida na Discovery } \\
\text { Kids. Foi exportada para os Estados Unidos e países da } \\
\text { Europa e mostra as aventuras de Lola, uma menina de } \\
\text { seis anos de idade que adora ciências. }\end{array}$ \\
\hline Mercúrio & $\begin{array}{l}\text { Personagem do filme } X \text {-Men: } \\
\text { dias de um futuro esquecido. }\end{array}$ & $\begin{array}{l}\text { É um personagem das histórias em quadrinhos do } \\
\text { Universo Marvel, publicadas pela Marvel Comics. No filme, } \\
\text { é representado por Evan Peters. Ele tem o poder da } \\
\text { velocidade, podendo viajar mais rápido que a velocidade } \\
\text { do som. }\end{array}$ \\
\hline Olaf & $\begin{array}{l}\text { Personagem do filme Frozen: } \\
\text { uma aventura congelante. }\end{array}$ & $\begin{array}{l}\text { É um personagem animado, um boneco de neve, criado } \\
\text { por Elsa. Ele ajuda as irmãs Elsa e Anna a vencerem } \\
\text { vários obstáculos na narrativa. }\end{array}$ \\
\hline $\begin{array}{l}\text { Harry } \\
\text { Potter }\end{array}$ & $\begin{array}{l}\text { Protagonista da cinessérie } \\
\text { Harry Potter. }\end{array}$ & $\begin{array}{l}\text { É um personagem interpretado pelo ator britânico Daniel } \\
\text { Radcliffe, o bruxo mais famosos da Escola de Magia e } \\
\text { Bruxaria de Hogwarts, onde se passa a narrativa. }\end{array}$ \\
\hline Coringa & $\begin{array}{l}\text { Antagonista de Batman. Está } \\
\text { em todos os filmes e } \\
\text { desenhos animados do super- }\end{array}$ & $\begin{array}{l}\text { É um supervilão que apareceu inicialmente nos } \\
\text { quadrinhos publicados pela DC Comics. Está presente } \\
\text { desde a revista número } 1 \text { do Batman. }\end{array}$ \\
\hline
\end{tabular}

Revista Digital do LAV - Santa Maria - vol. 13, n. 2, p. 254 - 273 - mai./ago. 2020 ISSN 1983 - 7348 http://dx.doi.org/10.5902/1983734844055 


\begin{tabular}{|c|c|c|}
\hline & herói. & \\
\hline Aruna & $\begin{array}{l}\text { Personagem da novela } A \\
\text { terra prometida produzida e } \\
\text { exibida pelo canal aberto TV } \\
\text { Record. }\end{array}$ & $\begin{array}{l}\text { É uma personagem representada pela atriz Thais Melchior, } \\
\text { uma das mocinhas da narrativa. }\end{array}$ \\
\hline Troll & $\begin{array}{l}\text { Personagem da animação } \\
\text { Trolls (2016). }\end{array}$ & $\begin{array}{l}\text { É um personagem troll. Os Trolls são um povo feliz que } \\
\text { vivem numa floresta, mas são perseguidos pelos Bergens. } \\
\text { A narrativa gira em torno das aventuras empreendidas } \\
\text { para se livrarem de seus inimigos e continuarem felizes. }\end{array}$ \\
\hline Owen & $\begin{array}{l}\text { Personagem do filme Jurassic } \\
\text { World: o mundo dos } \\
\text { dinossauros. }\end{array}$ & $\begin{array}{l}\text { É um personagem interpretado por Chris Pratt; um ex- } \\
\text { militar estadunidense que cuida dos dinossauros do } \\
\text { parque e os treina. Tem a missão de salvar o parque do } \\
\text { ataque de um dos dinossauros que foi criado } \\
\text { geneticamente. }\end{array}$ \\
\hline Maria & $\begin{array}{l}\text { Protagonista do filme João e } \\
\text { Maria: caçadores de bruxas. }\end{array}$ & $\begin{array}{l}\hat{E} \text { uma personagem interpretada pela atriz britânica } \\
\text { Gemma Arterton. É responsável, junto a seu irmão, de } \\
\text { eliminar as bruxas negras de um lugarejo na idade média. }\end{array}$ \\
\hline $\begin{array}{l}\text { Hazel } \\
\text { Grace }\end{array}$ & $\begin{array}{l}\text { Protagonista do filme } A \text { culpa } \\
\text { é das estrelas. }\end{array}$ & $\begin{array}{l}\text { É uma personagem representada por Shailene Woodley, } \\
\text { da série de filmes Divergente. É a mocinha do filme que, } \\
\text { com câncer no pulmão, conhece Augustus e juntos vão } \\
\text { conhecer a Holanda. }\end{array}$ \\
\hline João & $\begin{array}{l}\text { Protagonista do filme João e } \\
\text { Maria: caçadores de bruxas. }\end{array}$ & $\begin{array}{l}\text { É um personagem representado por Jeremy Lee Renner, } \\
\text { um ator, produtor cinematográfico, maquiador e ex- } \\
\text { músico estadunidense. É responsável, junto a sua irmã, } \\
\text { por eliminar as bruxas negras de um lugarejo na idade } \\
\text { média. }\end{array}$ \\
\hline Lola & $\begin{array}{l}\text { Personagem da animação } \\
\text { inglesa Charlie e Lola. }\end{array}$ & $\begin{array}{l}\text { É uma personagem criada pela escritora inglesa Lauren } \\
\text { Child. Os dois irmãos (Charlie e Lola) foram lançados } \\
\text { primeiramente em uma série de livros infantis e logo } \\
\text { depois em uma série de televisão. }\end{array}$ \\
\hline
\end{tabular}

Quadro 1: Nomes escolhidos pelos jovens e breve história Fonte: Elaboração própria

No quadro acima, só levamos em conta os nomes de personagens fictícios, pois é a análise deles que nos interessa. Vale assinalar alguns detalhes dessas escolhas:

- uma das meninas, escolheu uma personagem masculina (Owen, do filme Jurassic World: o mundo dos dinossauros);

- dos 14 meninos que participaram da pesquisa, 7 escolheram nomes de superheróis (Homem-Aranha, Batman, Hulk, Homem de Ferro, Wolverine, Thor e Mercúrio); um escolheu o nome de um supervilão (Coringa); dois escolheram nomes de personagens fortes e responsáveis por resolver os conflitos das narrativas (Kaulder e João); dois escolheram nomes de personagens não humanos (Troll e Olaf); e um optou pelo nome de um adolescente com poderes mágicos, que é quase um super-herói (Harry Potter);

- entre os nomes escolhidos pelas meninas, há uma personagem de novela (Aruna); 2 personagens de desenhos animados infantis (Luna e Lola); e todas as outras são personagens de filmes vistos ou comentados em sala de aula durante a pesquisa (Alice I, Alice II, Bella I, Bela II, Claire, Lúcia, Malévola, Lince Negra, Maria, Hazel Grace). 
O fato de muitos jovens do gênero masculino terem escolhido super-heróis de quadrinhos evidencia uma identificação com a força e o poder dos que se encontram acima e além dos humanos comuns, capazes de enfrentar todas as dificuldades e de correrem grandes riscos, sem hesitação. Talvez esses jovens se sintam impotentes diante dos desafios que Ihes são impostos pela condição masculina.

Kellner (2001), ao analisar Rambo, herói de guerra adaptado do romance (First Blood, de David Morrel) para o cinema pelo ator Silvester Stallone, em parceria com outros diretores (Ted Kotcheff, George P. Cosmatos, Adrian Grunberg, Peter MacDonald), Kellner (2001, p. 93), destaca o acentuado foco dado à força física e à imensa capacidade de resistência a diferentes tipos de injúria física e emocional:

O foco em seus bíceps luzidios, no seu corpo escultural e no físico poderoso apresenta-o como um símbolo sexual masculino, como um emblema de virilidade, que provoca a admiração das mulheres pela força masculina e talvez uma fascinação homoerótica pelo guerreiro masculino. As tomadas de cena em travelling e a câmera lenta codificam Rambo como uma força da natureza, que percorre a selva sem esforço, enquanto a música triunfante codifica seus feitos como super-heroicos. Sua regeneração como super-herói é apresentada em tomadas nas quais ele se projeta magicamente fora da água, purificado e potente, dignificado para vingar e triunfar (KELLNER, 2001, p. 93).

É interessante notar que os heróis e super-heróis, que foram escolhidos pelos jovens participantes deste estudo, vivenciam também experiências de regeneração quase infinitas, nas quais se curam, repetidamente, de inúmeros ferimentos que thes são impostos. Wolverine, por exemplo, em X-Men: dias de um futuro esquecido, cura-se imediatamente de tiros e facadas e até mesmo de uma explosão atômica. No entanto, luta contra a dificuldade para controlar a raiva, que coloca em risco as pessoas a quem ele preza. Em determinado momento, Wolverine é resgatado vivo, após vários dias submerso no fundo do mar, e sua aparência serena e lúcida sugere que a água talvez o tenha purificado de seu maior defeito: o descontrole emocional.

O filme João e Maria: caçadores de bruxas evidencia também a força física de João, que, assim como Rambo, progressivamente é elevado à categoria de super-herói pela ambientação do filme, pela trilha sonora, pelo movimento de câmeras e por outros elementos fílmicos que descrevem sua transformação de ser humano comum em herói indestrutível.

Os super-heróis que não têm aparência física forte, como Mercúrio, HomemAranha, professor Xavier (cadeirante), Batman e o Homem de Ferro, entre outros, apresentam poderes extra-humanos que compensam a força física e, por isso, mantém- 
se acima dos homens comuns. Isso foi observado nas argumentações de alguns jovens, ao serem perguntados especificamente sobre as personagens de $X$-Men: "De todas as personagens de $X$-Men: dias de um futuro esquecido, de qual você escolheria os poderes e as fraquezas? Por quê?":

Olaf: Eu escolheria os poderes e fraquezas do Mercúrio porque são vários poderes e uma só fraqueza, que pode ser controlada se eu quiser, se for paciente.

He-man: O professor Xavier, que fez esta escola, porque o poder dele é incrível! E eu não ligo de ter a fraqueza dele, porque se ele não tivesse passado por tudo isso que passou ele não conseguiria ficar bem com os humanos e não conseguiria lutar pelos direitos deles etc.

Thor: Eu escolheria [os poderes] do Mercúrio e a fraqueza do Wolverine, porque pra mim é fácil controlar as emoções.

As repostas indicam que, para eles, é possível trocar a força física pela intelectual ou pelo controle das emoções, desde que sejam também capacidades superiores às dos seres humanos comuns. Segundo a argumentação de um dos jovens, a personagem Mercúrio, por exemplo, tem a capacidade de se movimentar rapidamente, o que pode causar uma sensação de monotonia, pois ele vê o mundo em câmera lenta, mas, esse poder Ihe permite controlar sua fraqueza. O professor Xavier, por sua vez, é altamente inteligente e capaz de controlar as mentes dos outros, mas não tem o movimento das pernas, porém, para os jovens participantes da pesquisa, sua força intelectual sobrehumana supera sua deficiência física; enquanto Wolverine é forte fisicamente, mas extremamente fraco emocionalmente, o que, segundo os jovens, é um defeito menos grave, que pode ser superado. Os alunos argumentam ser possível compensar a falta da força física com a força intelectual ou emocional e vice-versa. No entanto, percebem que a força excepcional continua em evidência, ou seja, segue sendo uma característica dos heróis masculinos.

Foi possível perceber que os meninos não questionam a recorrência da representação masculina nos filmes endereçados à geração deles, como homens super fortes, com poderes infinitos de regeneração face à dor e aos ferimentos, resistentes e quase indestrutíveis. Conforme Jauss (1994), essa identidade masculina parece estar inserida no "horizonte de expectativas" (JAUSS, 1994) dos jovens espectadores contemporâneos, público alvo dessas narrativas. Como mencionado por Louro (2000), essa é uma identidade segura, construída ao longo de séculos e hegemonizada em sucessivas e permanentes repetições. Diante da desestabilização do papel masculino e do binarismo de gênero, ancorar-se em representações aparentemente sem ambiguidades 
pode dar uma falsa sensação de segurança e reconhecimento. A partir disso, vale questionar: as representações femininas, construídas nesses filmes, têm a mesma acolhida entre as meninas que as representações masculinas do herói indestrutível entre os meninos?

As meninas participantes, que responderam à atividade de escolha dos nomes, optaram por diferentes composições do feminino, desde a "mocinha sofredora" (Hazel Grace, Bella I, Bela II, Claire e outras) à anti-heroína (Malévola), ferida por um amor não correspondido; passando pela heroína com poderes sobre-humanos (Lince Negra). Essas escolhas indicam que, embora os filmes sigam reproduzindo e renovando padrões de identidade feminina, construídos ao longo da história do cinema, essas materialidades parecem não atender inteiramente às expectativas do público feminino. Talvez, porque as mudanças nos modos de representação do feminino, no audiovisual, sejam mais amplas, diversificadas e profundas em razão do crescimento do debate público em torno do tema. De um modo geral, essa é uma temática mais discutida, com maiores questionamentos por parte da sociedade, que os modos de representação do masculino, o que torna mais difícil a composição de personagens que correspondam às diferentes expectativas. No entanto, algumas características tradicionalmente atribuídas às mulheres, como uma leitura mais emocional do mundo, maior flexibilidade afetiva e maior abertura para opiniões alheias perseveram na maioria das representações do audiovisual hegemônico.

Em relação à construção das personagens femininas, mesmo tendo personalidades distintas, todas as escolhidas têm um padrão físico e estético parecidos: são brancas, de olhos claros, de aparência frágil e, com exceção da personagem de $A$ culpa é das estrelas (que vivenciava um tratamento contra o câncer), todas têm longos cabelos lisos. Psicologicamente, suas personalidades transitam entre o exercício do poder e um conflito, que as impede de exercê-lo plenamente. Essa é a trama de todas as narrativas: a crise de identidade que essas personagens vivenciam para atingir seus objetivos, confirmando a ideia de que são levadas a agir exclusivamente pela emoção.

Ao analisar filmes de guerra produzidos em Hollywood na década de 1980, Kellner (2001, p. 108) afirma: "A cultura da mídia produz imagens que mobilizam o desejo do espectador para certos modos de pensamento, comportamento e modelos que servem aos interesses da manutenção e da reiteração do status quo". Mais de 30 anos nos separam dos filmes analisados por Kellner, mas no sistema de produção industrial de narrativas cinematográficas dos Estados Unidos, de onde vêm a maioria dos produtos audiovisuais, a lógica de produção dos filmes e de composição de personagens ainda é a 
mesma: corresponder às expectativas do espectador médio e criar uma familiaridade que possibilite identificação; para isso, muitas vezes, as personagens seguem modelos e características que já foram aprovados e aceitos pelo grande público.

Esta padronização gera, aparentemente, uma sensação de conforto no espectador. Neste estudo, isso foi percebido, por exemplo, quando foi solicitado que os participantes recriassem o figurino da Katniss Everdeen, heroína vivida por Jennifer Lawrence no filme Jogos vorazes: a esperança - parte 1. A atividade consistia em desenhar o figurino da personagem em dois bonecos impressos e dizer em que ou em quem eles haviam se inspirado para criá-lo. Muitos optaram por fazer figurinos inspirados em outras personagens do cinema ou em pessoas que estavam em evidência nas mídias naquele momento. Eis o diálogo travado com a pesquisadora durante a atividade:

Pesquisadora: O Wolverine está me dizendo aqui que fez o dele inspirado na Angelina Jolie, em Tomb Raider, a Lara Croft.

Claire: Eu inspirei minha boneca no que eu vejo por aí.

Lince Negra: Os looks são inspirados no Superman, mas é um look mais para jantares, reuniões etc. Eu escolhi me inspirar nele, pois sempre que falam em heróis, eu me lembro dele.

Mercúrio: Inspirado na Psylocke, de X-Men Apocalipse.

Thor: Essas roupas foram inspiradas no $X-M e n$ e no Capitão América, mas acima de tudo no poder da mulher.

Homem de Ferro: Me inspirei em Tartarugas Ninjas, porque elas são muito flexíveis e têm vários golpes maneiros.

He-Man: O primeiro é baseado na She-ra, uma mulher que só faz o bem e o segundo é baseado no filme Elektra, uma heroína em ação.

Lola: Eu me inspirei em duas cantoras: Shakira e Beyoncé.

A personagem Lara Croft, inspiração do jovem Wolverine, é uma heroína dos jogos eletrônicos da série Tomb Raider, lançada em 1996. Ao todo, a série conta com seis jogos e cerca de 89 milhões de unidades vendidas, que levaram Lara Croft para o Guiness Book como a heroína mais bem-sucedida no mundo dos games. Em 2001, o jogo virou filme e a atriz Angelina Jolie interpretou a protagonista. O filme Lara Croft: Tomb Raider (Simon West, 2001) se tornou o mais lucrativo e estrelado por uma mulher, bem como o de maior bilheteria de uma adaptação de jogo para o cinema, alcançando duas sequências, uma lançada em 2003 e outra em 2018.

Em relação ao figurino, a personagem veste sempre roupas muito justas e sensuais, de tecidos maleáveis, que demarcam bem as formas de corpo 'perfeito', segundo os padrões de beleza feminina; são em geral roupas esportivas, algumas 
remetem ao hipismo; os cabelos são muito longos e pretos, arrumados em uma trança apertada ou rabo de cavalo, para não atrapalhar seus movimentos rápidos e intensos. Em algumas cenas, a personagem usa óculos escuros.

Psylocke, inspiração do jovem que se autoidentifica como Mercúrio, é uma personagem dos quadrinhos, do cinema e também dos games. No filme mencionado pelo jovem ( $X$-Men apocalipse), a mutante (interpretada pela atriz estadunidense Olivia Munn) aparece com maiô de látex e uma meia-calça de mesmo tecido com vários furos na altura da perna. Na época do lançamento do filme, várias matérias destacavam o figurino vulgar da heroína e, em entrevistas, a atriz defendia o figurino como sendo sexy e fiel à personagem dos quadrinhos.

Elektra, a personagem dos quadrinhos Marvel, que foi uma das inspirações do jovem autoidentificado como He-man, foi eleita uma das 100 mulheres mais sensuais dos quadrinhos. Ela usa maiô ou biquíni vermelho decotado e com inúmeras fendas, com adereços esvoaçantes e fitas sobrepostos aos braços e pernas, o que evidencia um corpo musculoso, com curvas bem delineadas e pernas torneadas; usa os longos cabelos castanhos soltos com um lenço no alto da cabeça, do mesmo tecido da roupa para compor o visual.

Os outros heróis e heroínas que inspiraram as criações dos participantes das oficinas usam macacões de látex colados no corpo e capas, como Superman e She-Ra esta é uma das poucas heroínas que usa minissaia acompanhada de maiô e capa.

É interessante notar que uma das meninas, a de nome Lola, se inspirou em duas cantoras pop, cujos figurinos de shows são parecidos com os das heroínas citadas pelos demais: maiôs ou macacões de látex, bem colados no corpo, acentuando curvas e músculos bem delineados. Há, em certa medida, um mesmo padrão estético nos figurinos das heroínas e dessas estrelas da música pop internacional.

Foi possível perceber também que, apesar da proposta da atividade ser a de desenhar o figurino da personagem, a maioria dos participantes se preocupou também com o cabelo ou com um adereço. Todos os cabelos eram longos, o que ocorre também com as personagens que usaram como inspiração. Fica evidente a reprodução de alguns elementos da já tradicional representação de mulheres poderosas: botas quase sempre longas, roupas que destacam o corpo, como maiôs, corpetes e macacões de tecidos aderentes e bastante justos, cabelos longos e lisos. Um modelo de herói ou heroína na maioria das vezes bem diferente deles próprios. 
Algumas meninas optaram por atribuir à personagem um figurino que elas mesmas gostariam de usar, inspirando-se, segundo elas, em seus gostos para se vestir:

Aruna: Porque eu gosto desta roupa, amo!

Bela II: É uma roupa que combina com ela e se identifica com o meu estilo.

Malévola: Essa roupa é baseada em mim.

Susana: Eu fiquei inspirada no meu jeito de vestir e várias outras maneiras.

Vale destacar que os figurinos criados pelas quatro jovens participantes da pesquisa, cujas falas aparecem em destaque acima, eram os mais comuns: a primeira desenhou uma minissaia, tênis e top; a segunda optou por um figurino com salto alto, saia longa e camisa social; a terceira criou um figuro com short e boné; e a última desenhou uma calça jeans larga acompanhada de um top e tênis de salto. Nenhum desses quatro figurinos apresentava um símbolo, arma ou qualquer menção ao fato de estarem direcionados a uma super-heroína.

Para essas quatro jovens, o figurino deixou de ser o de uma heroína e passou a ser a projeção delas próprias na heroína, ou seja, elas conseguiam se ver no lugar da personagem e talvez experimentar vê-la em si mesmas. De certo modo, colocar as próprias roupas no corpo da personagem indica a humanização da figura ficcional, que se tornaria uma mulher comum, assim como a possibilidade de acesso das meninas à condição de uma mulher com poderes especiais. Uma identidade camisa, em busca talvez de uma identidade pele, na perspectiva de García Canclini (2005).

Diferente do figurino dos super-heróis masculinos, que demarca a força física, mas indica também mobilidade, autodefesa e poder de ação, o figurino das heroínas, na maior parte das vezes, acentua, fundamentalmente, um suposto poder maior dessas mulheres: o poder de sedução. Acentua-se a sensualidade em corpos volumosos e firmes, com curvas delicadas, lábios grossos e cabelos longos (em muitas culturas, cabelos são expressão da sexualidade feminina), o estereótipo típico da mulher fatal, que seduz para derrotar.

Seguem sendo mantidos, portanto, padrões de representação de personagens femininas e masculinas que ainda agradam ao público jovem, não necessariamente, porque esse público não questione esses padrões, mas talvez porque lidar com o conhecido e esperado seja menos desafiador do que se deixar desestabilizar pela novidade. 


\section{Considerações}

Nos filmes que compuseram o estudo aqui mencionado (listados entre as 20 maiores bilheterias de cinema de 2014), persistem estereótipos na representação de personagens femininas e masculinas. No entanto, ainda assim, agradam ao público ao qual são endereçados, a julgar pelos espetaculares números de ingressos vendidos. Nesses filmes, os protagonistas masculinos são caracterizados por sua força física, sua inteligência excepcional e sua quase indestrutibilidade, enquanto as protagonistas femininas são lindas, magras, sensuais, inteligentes, mas facilmente manipuláveis e agem por impulso, geralmente, em questões emocionais. As garotas e os garotos acompanhados na pesquisa não se sentiram incomodados com esses estereótipos e quase não os contestaram, mostrando que, de certa maneira, estão confortáveis com esses modos de representação.

É importante reconhecer que o monopólio do mercado audiovisual por um pequeno número de megacorporações, sediadas nos EUA (Warner, Universal, Sony, MGM, Disney, Dreamworks, Fox, entre outras), contribuiu significativamente para que haja uma padronização de estruturas narrativas e de modos de representação tanto no que se refere à lógica de produção (tipo de produto colocado no mercado) quanto no que diz respeito à lógica de recepção, pois o acesso a um formato e estruturas mais ou menos uniformes tendem a padronizar, também, o gosto e as expectativas do espectador. Por outro lado, como assinala Martín-Barbero (2013), a relação síncrona entre a lógica de produção e a lógica de recepção sugere que mudanças nas expectativas dos receptores quanto à abordagem de determinados temas podem provocar transformações na forma como estes são tratados pelas mídias.

Assim, ao que parece, os modos de representação de gêneros binários hegemonizados, nos filmes mencionados, seguem atendendo às expectativas do público a quem são endereçados. Para efetivar mudanças significativas nas concepções de gênero, é necessário atuar nas duas frentes ao mesmo tempo: junto aos jovens, questionando concepções binárias e cristalizadas, bem como modos de representação de gênero; e junto aos criadores de conteúdo audiovisual, exigindo inovação e incorporação da pluralidade e da diversidade no discurso e na estrutura narrativa dos produtos.

Ao final das oficinas, percebemos que os jovens participantes começavam a adotar alguns critérios de qualidade na análise dos filmes, formulando questionamentos e críticas, mas pareciam se sentir confortáveis com as escolhas estéticas e com os padrões narrativos adotados na composição de personagens e de narrativas. Houve, dessa forma, 
uma maior criticidade no olhar quanto aos aspectos técnicos e estéticos, mas não uma crítica a valores, o que sugere que a aquisição de conhecimentos sobre a linguagem audiovisual não implica necessariamente mudança nas expectativas quanto ao tratamento dos temas.

Percebemos, ainda, a importância de criarmos, no cotidiano das escolas, espaços e condições para o diálogo permanente dos estudantes com a produção audiovisual, priorizando qualidade, diversidade e pluralidade, na perspectiva de uma educação para as mídias, que envolva a compreensão e análise crítica da linguagem, da estrutura narrativa, da lógica de produção e das estratégias de poder.

\section{Referências}

ALVES, P.; COELHO, P. Discursos, performatividades e padrões visuais no cinema: reflexões sobre as representações de gênero, o mercado cinematográfico e o cinema de mulheres. ACENO, vol. 2, n. 3, p. 159-176, jan./jul. 2015. Políticas e Poéticas do Audiovisual na contemporaneidade: por uma antropologia do cinema (dossiê).

ANDERSON, H.; DANIELS, M. Film Dialogue. Disponível em: <https://pudding.cool/2017/03/film-dialogue/>. Acesso em: 21 abr. 2020.

AGÊNCIA NACIONAL DO CINEMA (Ancine). Informe de acompanhamento do mercado. Distribuição em Salas de Exibição - Informe Anual 2014. Publicado no Observatório Brasileiro do Cinema e do Audiovisual (OCA) em 27 maio 2015. Disponível em: <http://oca.ancine.gov.br/sites/default/files/cinema/pdf/Anuario_2014.pdf>. Acesso em: 06 set. 2015.

ANDRADE, M.; LUCINDA, M. da C. Oficinas pedagógicas em direitos humanos: uma aposta de formação política com grupos populares. In: CANDAU, V. M.; SACAVINO, S. (Org.). Educar em tempos difíceis: construindo caminhos. Rio de Janeiro: 7Letras, 2011. p. 253-272.

DIONNE, H. A pesquisa-ação para o desenvolvimento local. Tradução de Michel Thiollent. Brasília: Liber Livro Editora, 2007.

CANCLINI, N. G. Diferentes, desiguais e desconectados: mapas da interculturalidade. Tradução de Luiz Sérgio Henriques. 3. ed. Rio de Janeiro: Editora UFRJ, 2015.

JAUSS, H. R. A história da literatura como provocação à teoria literária. São Paulo: Editora Ática, 1994.

KAMITA, R. C. Relações de gênero no cinema: contestação e resistência. Revista de Estudos Feministas, vol. 25, n. 3, p. 1393-1404, Florianópolis, set./dez, 2017.

KAPLAN, E. A. A mulher e o cinema: os dois lados da câmera. Tradução de Helen Potter Pessoa. Rio de Janeiro: Rocco, 1995. 
KELLNER, D. A cultura da mídia: estudos culturais - identidade e política entre o moderno e o pós-modernos. Tradução de Ivone Castilho Benedetti. Bauru. São Paulo: EDUSC, 2001.

LOURO, G. L. O cinema como pedagogia. In: LOPES, E. M. T.; FILHO, L. F. M.; VEIGA, C. G. (Org.). 500 anos de educação no Brasil. 2. ed. Belo Horizonte: Autêntica, 2000. p. 423-446.

LOURO, G. L. Cinema e sexualidade. Educação e Realidade, v. 33, n. 1, p. 81-98, jan./jun. 2008.

LOURO, G. L. Destemidos, bravos, solitários: a masculinidade na versão western. Bagoas, n. 10, p. 171-182, 2013. Disponível em: <http://periodicos.ufrn.br/bagoas/article/download/5382/4397>. Acesso em: 14 out. 2015.

LUSVARGHI, L; ALVIM, L. B.; NASCIMENTO, G. (Org.). Cinema, representação e relações de gênero. Ebook. Editora: e-galaxia, 2018.

MARTÍN-BARBERO, J. Dos meios às mediações: comunicação, cultura e hegemonia. Tradução de Ronald Polito e Sérgio Alcides. 7. ed. Rio de Janeiro: Editora UFRJ, 2013.

MORIN, E. As estrelas: mito e sedução no cinema. Tradução de Luciano Trigo. Rio de Janeiro: José Olympio, 1989.

ORTIZ, R. Mundialização e cultura. 3. ed. São Paulo: Brasiliense, 1994.

SARLO, B. Cenas da vida pós-moderna: intelectuais, arte e videocultura na Argentina. Tradução de Sérgio Alcides. 5. ed. Rio de Janeiro: Editora da UFRJ, 2013.

VEIGA, A. M. Gênero e cinema, uma história de teorias e desafios. Apresentação de Seção Temática. Revista de Estudos Feministas, v. 25, n. 3, p. 1355-1357, Florianópolis, set./dez. 2017.

\footnotetext{
' Graduada em Letras pela Universidade Federal de Viçosa (UFV). Mestra em Educação pela Universidade na linha de Pesquisa Linguagem e Formação de Professores Federal de Juiz de Fora (UFJF). Doutora em Educação na Pontifícia Universidade Católica do Rio de Janeiro (PUC/Rio) na Linha de Pesquisa Processos Culturais, Instâncias da Socialização e a Educação.

ii Possui graduação em Psicologia pela Universidade do Estado do Rio de Janeiro (1984), mestrado em Educação pela Fundação Getúlio Vargas - RJ (1991) e doutorado em Educação pela Pontifícia Universidade Católica do Rio de Janeiro (2000).
}

Como citar esse artigo:

MACHADO, Carla Silva; DUARTE, Rosália Maria. Relatos de uma pesquisa com jovens estudantes de Juiz de Fora: audiovisual e gênero. Revista Digital do LAV, Santa Maria: UFSM, v. 13, n. 2, p. 254-273, mai./ago. 2020. 